\title{
VARIAÇÃO DO NÚMERO DE ESTÔMATOS E MICROPÊLOS EM PASPALUM VAGINATUM SW. EM RELAÇÃO ÀS CONDIÇÕES ABIÓTICAS NUMA MARISMA DO ESTUẢRIO DA LAGOA DOS PATOS, RS-BRASIL ${ }^{1}$
}

\author{
Eleci de Oliveria Bastos ${ }^{2}$ \\ Mara Perazzolo ${ }^{3}$ \\ Jusseli Maria Rocha Baptista ${ }^{4}$
}

Recebido em 16-09-91. Aceito em 17-03-93

RESUMO: Paspalum vaginatum Sw., gramínea perene, estolonífera, com folhas anfistomáticas e pequenas é característica de pântanos salgados, crescendo em condiçôes estressantes na marisma da lagoa dos Patos, molhe oeste da Barra do Rio Grande, RS.

Foram feitas contagens mensais de estômatos e micropêlos nas superfícies adaxial e abaxial das lâminas e relacionadas às características abióticas do ambiente. O número de micropêlos da superfície foliar abaxial variou significativamente e diretamente com a temperatura da água intersticial junto às rizosferas. Estes, porém, não mantiveram correlaçăo com a salinidade intersticial. Os resultados sugerem que a espécie seja uma halófita facultativa. O número de estômatos da superfície abaxial manteve um relacionamento inverso com a pluviosidade. Paspalum vaginatum, apresenta-se como uma espécie com características xeromórficas.

Palavras-chave: Paspalum vaginatum, adaptaçōes, marisma, características abióticas.

ABSTRACT: Paspalum vaginatum Sw., a perennial, stoloniferous grass with small leaves presenting stomata on both epidermises is characteristic of salt marshes, growing under stressful conditions near the west breakwater of the Rio Grande outlet, Lagoa dos Patos, Rio Grande do Sul, Brazil.

1 - Trabalho apresentado no XLII Congresso Nacional de Botânica, Goiânia (GO).

2 - Bolsista de Iniciaçāo Científica FAPERGS (proc. 1848). Av. dos Arquipélagos, 39 96215-000 - Rio Grande - RS.

3 - Depto de Ciências Morfo-Biológicas - URG - CP.474, 96500-900 - Rio Grande - RS.

4 - Depto de Química (Lab. Hidroquímica) - URG - CP.474, 96500-900 - Rio Grande - RS. 
Monthly counts of stomata and microhairs on the adaxial and abaxial surfaces were related to the abiotic characteristics of the enviroment. The number of microhairs of the abaxial leaf surface varied significantly and directly with interstitial water temperature close to the rhyzosphere. However, these counts did not correlate with the interstitial salinity. The results suggest that the species is a facultative halophyte. Stomata counts of the abaxial surface showed an inverse relation to precipitation. Paspalum vaginatum appears to be a species with xeromorphic characteristics.

Key-Words: Paspalum vaginatum, adaptations, salt marsh, abiotic characteristics.

\section{Indrodução}

Marismas e brejos são ambientes do ecossitema estuarino da Lagoa dos Patos, cujas áreas totalizam 4000 ha. (Asmus et al., 1989). Em geral, a vegetação destes ambientes é responsável pelo alimento, habitat e refúgio oferecidos à fauna e pelo fornecimento de matéria orgânica e nutrientes inorgânicos, originados de sua deconposição, às águas superficiais e interstitiais. A vegetação, de uma maneira geral, pode se apresentar resistente a algumas ou todas as condições estressantes (Levitt, 1980.. As marismas são estressantes pela alta salinidade e alagamento, que induzem a modificações morfológicas, anatômicas, fisiológicas, entre outras, podendo ocorrer significativas mudanças na densidade de estômatos e tricomas sob condições de extremas variações. $\mathrm{O}$ aumento significativo na densidade estomática de espécies xerofíticas, expostas ao estresse hídrico acompanhado de condições climáticas extremas, foi analisado por Maximov (1931), Gindel (1969a, b) e Leras (1977). Assim como alterações do número de estômatos (Waisel, 1972 e Dillenburg et al., 1986), tricomas e glândulas de sal (Liphschitz \& Wasisel, 1982) são influenciadas pelka salinidade. Micropelos de gramíneaes das subfamílias Chloridoideae e Panicoideae foram analizados ultra-estruturalmente de acordo com a atividade secretora de sal e classificados como "cloridóide" e "panicóide" (Amarasingue \& Watson 1988, 1989).

O presente trabalho visa quantificar estômatos e micropêlos de Paspalum vaginatum e relacionar as densidades das estruturas epidérmicas com as condições abióticas das águas intersticiais junto à rizofera e com a pluviosidade, a fim de investigar uma provável resposta adaptativa xero-halofítica; o trabalho visa, ainda, caracterizar vários parâmetros hidrofisico-químicos da marisma sob estudo.

\section{Materiais e métodos}

A marisma em estudo é uma baia fechada, irrergulamente alagada, que apresenta um canal de ligação com a porção sul do estuário da Lagoa dos Patos $\left(32^{\circ} 9^{\prime} \mathrm{S} 52^{\circ} 6^{\prime} \mathrm{W}\right)$ (Figura 1).

As coletas de $P$. vaginatum realizaram-se mensalmente desde abril de 1989 a novembro de 1990, enquanto as coletas de águas superficial foram interrompidas de março de 1990. A partir de setembro 1989 passou-se a coletar água intersticial 


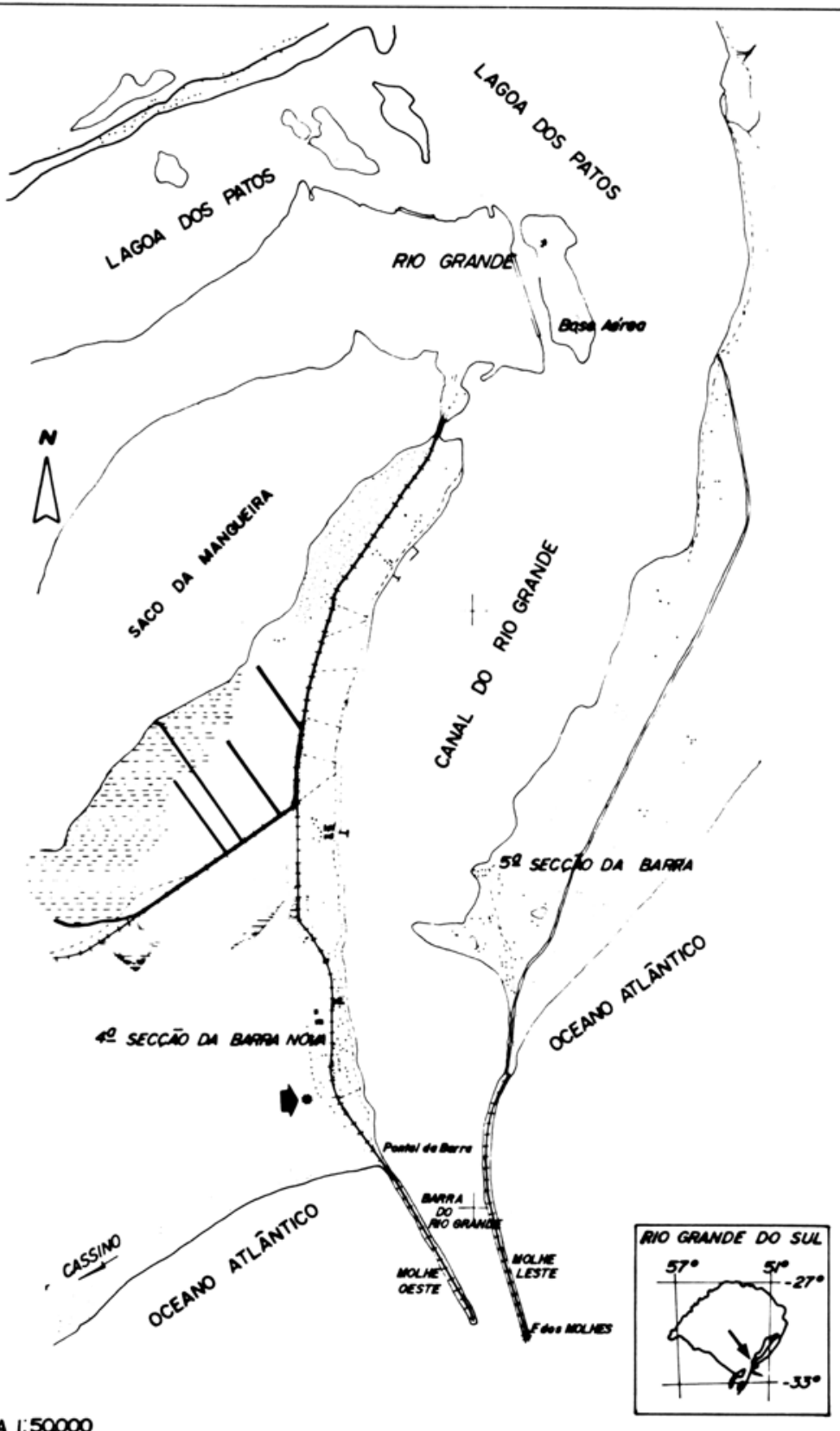

Figura 1 - Mapa da região de coletas. Estuário da Lagoa dos Patos, Rio Grande, Rio Grande do Sul. $\Rightarrow *$ Local de coletas. 
junto ao sistema radicular de $P$. vaginatum. O exemplar testemunho ("Voucher") de $P$. vaginatum, M. Perazzolo $\mathrm{s} / \mathrm{n}^{2}, 24$.V.1988. (HURG 002114).

As plantas escolhidas para estudo encontravam-se numa pequena área, 11 a $20 \mathrm{~cm}$ acima do nível da água superficial e cujo substrato eventualmente achava-se submerso.

A água superficial foi coletada no corpo principal, a $5 \mathrm{~m}$ de uma margem externa, elevada e coberta por Spartina Schreber. A água intersticial foi obtida a cerca de $20 \mathrm{~cm}$ de profundidade, empregando-se um cilindro coletor de PVC, metodologia adaptada de WEBB (1983), mantido permanentemente junto ao sistema radicular.

As amostragens e as análises físico-químicas das águas foram realizadas segundo métodos específicos descritos por GRASSHOFF et al., 1983.

Os índices pluviométricos, obtidos nos quinze dias anteriores a cada coleta, foram fornecidos pela Estação de Coletas de Dados Meteológicos de Superfície - Departamento de Geociências da Fundação Universidade do Rio Grande, Rio Grande - RS.

O tratamento dos resultados compreendeu o cálculo dos coeficientes de variação e do coeficiente de correlação linear simples, através de versão 1.2 Relize 5 (1987), APLICATION SYSTEM-IBM, adotando-se níveis de confiança de $90 \%, 95 \%$ e $99 \%$.

\section{A - Metodologia Abiótica}

A Tabela 1 mostra as diversas metodologias de coleta adotadas com as respectivas análises efetuadas.

Tabela 1 - Metodologia de coleta e análises das águas superficial e intersticial.

\begin{tabular}{|c|c|c|}
\hline Amostras & Variáveis & Metodologia de Coleta e Análises \\
\hline \multirow{5}{*}{$\begin{array}{l}\text { Água } \\
\text { Superficial }\end{array}$} & Temperatura & $\begin{array}{l}\text { Tomada "in situ", com termômetro de HG } \\
\pm 0,1 \mathrm{C} \text { de precisão. }\end{array}$ \\
\hline & $\mathrm{pH}$ & $\begin{array}{l}\text { Em laboratório, por método } \\
\text { potenciométrico } \pm 0,1 \text { unidade de preçisāo. }\end{array}$ \\
\hline & Salinidade & $\begin{array}{l}\text { Em laboratório, por método refratométrico, } \\
\pm 1 \% \text { de precisāo. }\end{array}$ \\
\hline & Amônio e Fosfato & $\begin{array}{l}\text { Dosados, na fraçāo filtrada em filtro de } \\
\text { acetato de celulose com poros de } 0,45 \mu \mathrm{m}\end{array}$ \\
\hline & Oxigênio dissolvido & $\begin{array}{l}\text { Fixado "in situ" e dosado em laboratório } \\
\text { por método iodométrico. }\end{array}$ \\
\hline \multirow{2}{*}{$\begin{array}{l}\text { Água } \\
\text { Intersticial }\end{array}$} & Temperatura & $\begin{array}{l}\text { Tomada “insitu”, com termômetro de } \\
\mathrm{Hg}, \pm 0,1 \mathrm{C} \text { de precisāo. }\end{array}$ \\
\hline & Salinidade & $\begin{array}{l}\text { Em laboratório, por método } \\
\text { refratométrico, } \pm 1 \% \text { de precisāo. }\end{array}$ \\
\hline
\end{tabular}


B - Metologia Biótica

Plantas inteiras de $P$. vaginatum foram coletadas com parte do substrato e transportadas para o laboratório em bandejas de plástico.

Foram utilizadas no total 12 lâminas foliares por mês, tendo sido selecionada a segunda lâmina foliar inteira, totalmente expandida, a partir do ápice. Estas foram seccionadas na sua porção mediana e tratadas com hipoclorito de sódio quente. As epidermes foram lavadas com água destilada, coradas com Giemsa e montadas em lâminas semipermanentes com glicerina fenicada.

Para análise de densidade de estômatos e micropêlos realizaram-se três contagens para cada superfície (adaxial e abaxial). O total mensal de contagens para cada estrutura foi 72 . Todas as contagens foram feitas com microscópio óptico binocular com aumento de 400 vezes, numa área de $0,17 \mathrm{~mm}^{2}$. O número de micropêlos e estômatos contados nesta área são representados respectivamente pelas abreviações MP1 e ET1 para superfície adaxial, e MP2 e ET2 para abaxial. As medidas de comprimento e largura foram realizadas em 100 lâminas foliares, nos meses de dezembro (verão) e junho (inverno).

Para análise anatômica das estruturas epidérmicas, em vista frontal, foram feitas descolamento com hipoclorito de sódio a quente e coradas com Sudan IV.

Para confecção de lâminas permanetes utilizou-se a segunda lâmina foliar a partir do ápice, sendo fixadas em ALFAC. A técnica de inclusão em parafina foi feita pelo método de Preece (Beçak \& Paulete, 1976) e seccionadas com espessura de $17 \mu \mathrm{m}$ em cortes longitudinais. A coloração foi feita em Astrablau-AuraminaSafranina (Maácz \& Vágas, 1961). As estruturas foram analizadas e desenhadas em microscópio óptico com câmara clara. Foram obtidas medidas através de régua micrometrada por transferência, sendo os valores referidos em micrômetros $(\mu \mathrm{m})$.

\section{Resultados e Discussão}

A - Parâmetros Abióticos.

TEMPERATURA. A temperatura intersticial variou de um mínimo de cerca de $22^{\circ} \mathrm{C}$ em fim de outrobro ao máximo de cerca de $27^{\circ} \mathrm{C}$ no verão (Figura 6 ). No mesmo período, a variação da temperatura superficial foi mais extrema $\left(8^{\circ} \mathrm{C}\right)$, tendo ocorrido o gradiente máximo entre elas $\left(7,3^{\circ} \mathrm{C}\right)$ na primavera (Figura 10).Nos meses de alta pluviosidade $(60 \mathrm{~mm})$ o equilíbrio térmico entre as águas provavelmente refletiu o estado de submergência (alagamento) do substrato (Figura 7).No verão, as flutuações da temperatura e da salinidade intersticiais estiveram diretamente associadas, evidenciando a influência da evaporação (aumento da temperatura, aumento da salinidade) e da chuva local (diminuição da salinidade, acompanhada de abaixamento da temperatura) sobre as alterações da água do substrato (Figuras 6 e 8). 


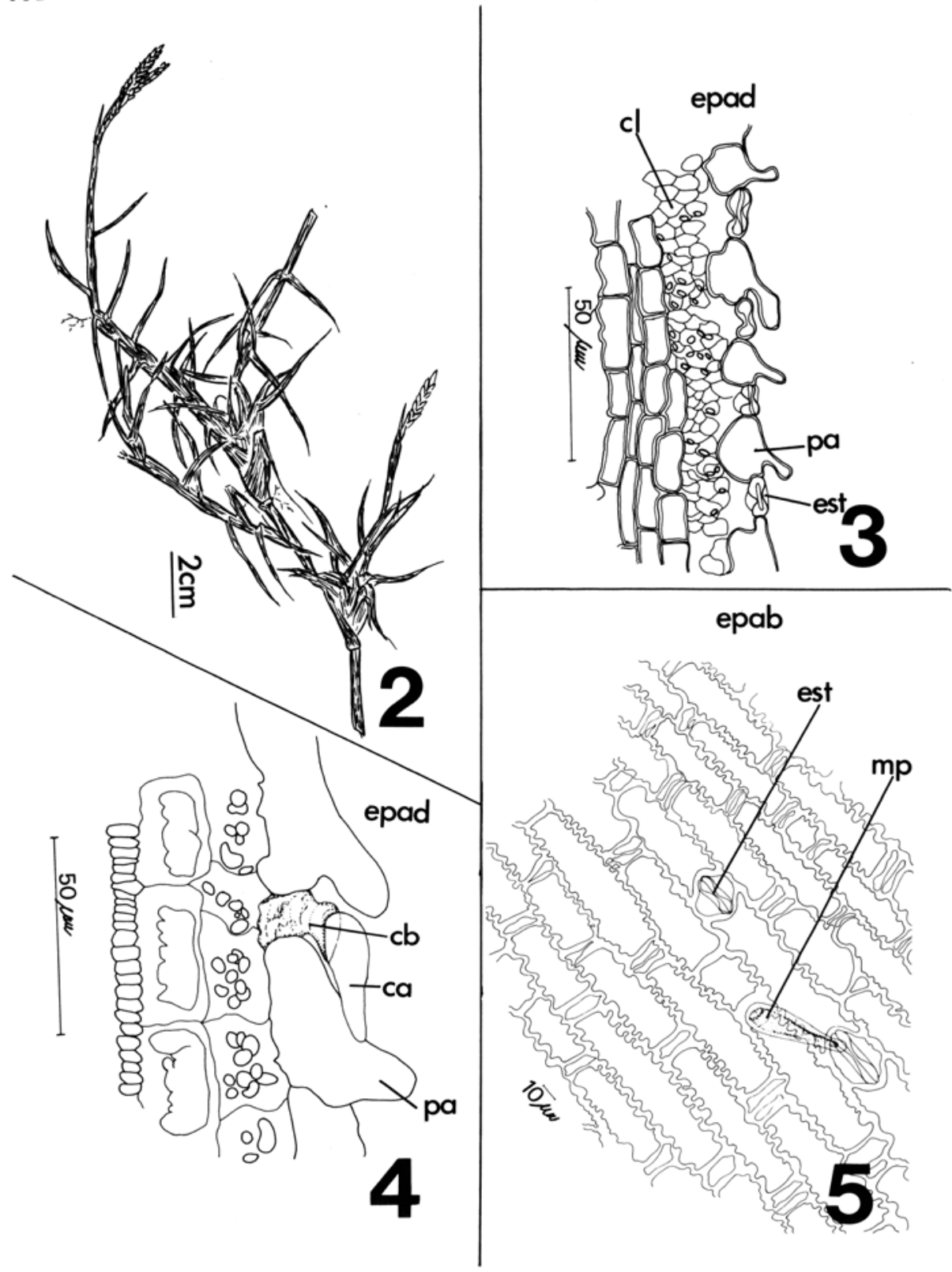

Figura 2 a $5: 2$. P. vaginatum. Aspecto geral. 3. P. vaginatum. Corte longitudinal da lâmina foliar. epad: epiderme adaxial; est: estômato; cl; clorênquima; pa: epiderme papilosa. 4. P. vaginatum. Corte longitudinal da lâmina foliar. epad: epiderme adaxial; ca: célula apical; cb: célula basal - micropêlo do padrão anatômico "panicóide"; pa: epiderme papilosa. 5. P. vaginatum. Vista frontal da superfície abaxial. epab: epiderme abaxiai; est: estômato; mp: micropêlo. 
SALINIDADE. A salinidade superficial na marisma variou de um máximo no verão de $37,5 \%$ a um mínimo de $2,5 \%$ em períodos de chuva intensa $(r=-0,50)$. No outono e inverno, com precipitações inferiores a $40 \mathrm{~mm}$, a salinidade mantevese superior a $20 \%$ •(Figura 8 ). As flutuações observadas podem ser atribuidas também ao aumento da evaporação e transpiração no verão (Chapman, 1974) e entrada de água marinha. De fato, os sedimentos expostos, durante o verão, apresentaram um crosta salina. Considerando o período de setembro 1989 a março 1990 , a diferença entre as amplitudes de variação das salinidades do corpo principal (2,5 a $37,5 \%$ o) e da água do sedimento (12,5 a $25 \%$ o) foi acentuada. Um dos fatores que explicaria a estabilidade salina da água intersticial é a entrada de água subterrânea, principalmente no verão, quando registrou-se o gradiente máximo de $20 \%$ • entre as águas.

$\mathrm{pH}$. O pH médio da marisma foi 8,00 levemente inferior ao da água marinha, mas em concordância com outros ambientes de pântanos salgados (Pomeroy \& Imberger, 1981). Devido a sua fraca variação estacional (1,1 unidades de $\mathrm{ph})$ (Figura 9), 0 ph demostrou um comportamento conservativo, também sugerido pela falta de uma correlação significativa com a salinidade.

Aumentos de $\mathrm{pH}$ relacionaram-se diretamente às condições oxidantes $(\mathrm{r}=0,77$ com oxigênio e percentual de saturação) da água superficial. Potencial redox e pH são fatores importantes que governam a decomposição da matéria orgânica (Delaune et al., 1981; Hambrick III et al., 1980) e a inter-relação entre eles é altamente variável em ambientes naturais (Becking et al. 1960).

OXIGÊNIO DISSOLVIDO. O oxigênio dissolvido variou entre o mínimo sub-saturado de 2,5ml/1 (48\% de saturação) e o máximo de $8,3 \mathrm{ml} / 1$ (150\% de saturação), revelando um ambiente em geral aerado (98\% de saturação em média) (Figura 9).

As flutuações sazonais parecem acompanhar as variações na temperatura (maior saturação no outono/inverno), mostrando um "Déficit" acentuado no verão (Figura 9 e 10).

O relacionamento altamente significativo $(r=0,97)$ entre o teor de oxigênio e o percentual de saturação sugere um balanceamento entre os vários mecanismos, ou fontes, de consumo e aqueles de produção de oxigênio, conjuntamente com as variações em temperatura e salinidade.

Em concordância com os estudos de Khalid et al. (1978) e Patrick \& Delaune (1977), em estuários e pantânos costeiros, as correlações significativas ( $\mathrm{r}=-0,56$ e $=0,50$ ) do oxigênio com os nutrientes dissolvidos salientaram que os nutrientes estavam em maior disponibilidade na água sob condições menos oxidantes.

FOSFATO E AMÔNIO DISSOLVIDOS. A marisma mostrou-se, no ciclo anual, uma ambiente eutrofisado em relação a fosfato, com a alta concentração mínima de $2,5 \mu \mathrm{M}$. Porém, amônio esteve praticamente ausente da água no inverno e fim da primavera (Figura 10).

As flutuações dos nutrientes estiveram significativamente inter-relacionadas $(r=0,65)$ e seus acentuados aumentos associaram-se à elevação da temperatura 

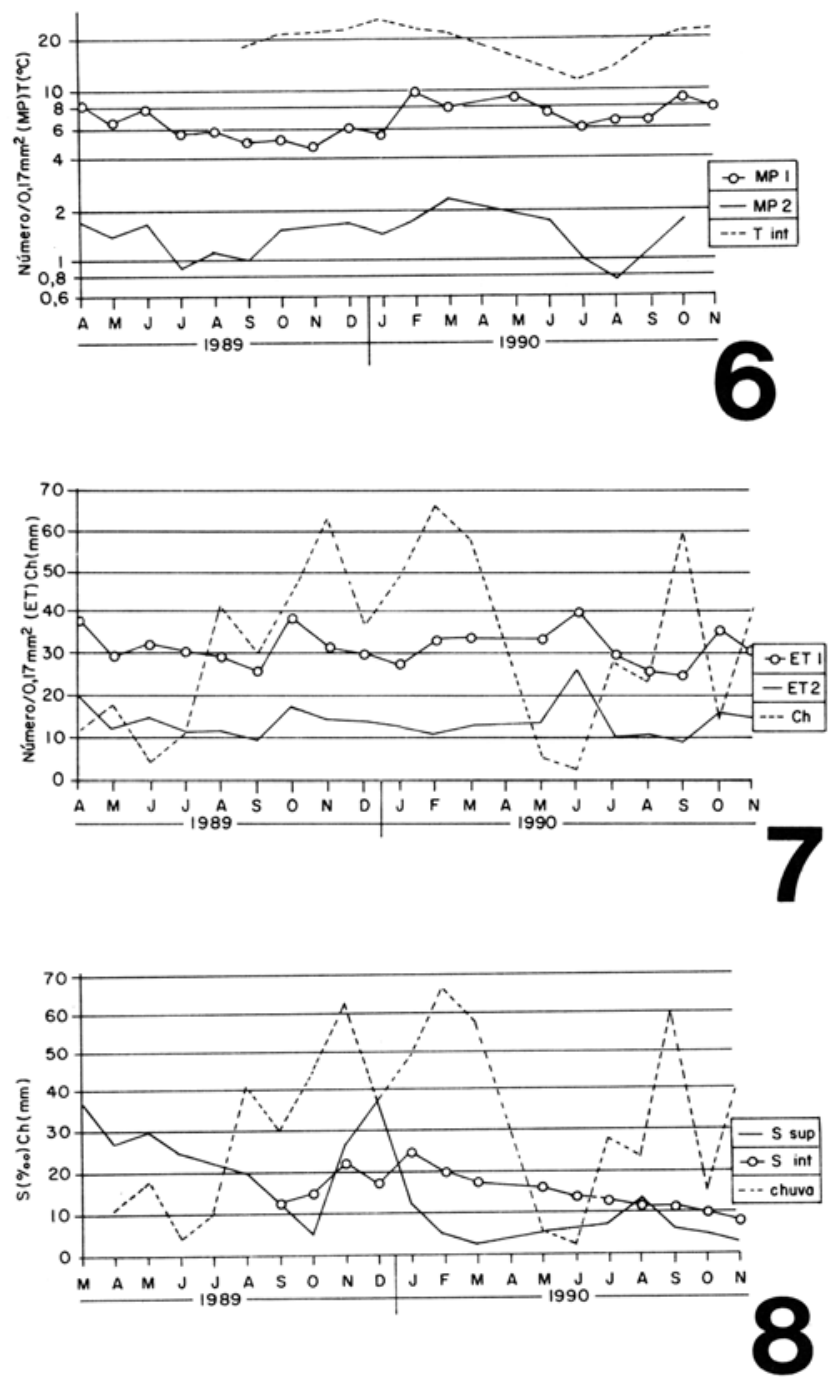

Figura 6 a 8: 6. Variação mensal dos micropêlos das faces adaxial (MP1) e abaxial (MP2) e da temperatura intersticial (T.int.). 7. Variação mensal dos estômatos das faces adaxial (ET1) e abaxial (ET2) e da pluviosidade local. 8. Variação mensal das salinidades superficial (S. sup.) e intersticial (S. int.) e pluviosidade local. 
$(r=0,52$ e 0,49$)$. Parece ser um padrão comum dos sistemas marinhos rasos os máximos estival de fosfato $\mathrm{e}$ amônio, que tem sido atribuídos à remineralização do material orgânico de fundo (Nixon, 1982) e também à perda de fosfato dos sedimentos onde as águas de fundo tornam-se anóxicas (Patrick \& Delaune, 1977 e Pomeroy et al., 1965). O fosfato e o amônio resultantes, em consequência, se apresentaram na água em teores superiores a $15 \mathrm{~mm}$ e $35 \mathrm{~mm}$, respectivamente, no verão. De fato, existiu matéria orgânica disponível nos sedimentos da marisma (1,2 a $3,1 \%$ carbono p.s.) e temperaturas mais mornas, favorecendo a degradação e mineralização, o que justificariam os máximos simultâneos dos nutrientes.

B - Parâmetros bióticos.

A marisma estudada é dominada por gramíneas do gênero Spartina; a área ocupada por $P$. vaginatum (Figura 2) representa uma fração muito pequena do total coberto pela vegetação. Esta espécie, característica de pantânos salgados, forma um denso tapete folioso no local.

As folhas de $P$. vaginatum caracterizam-se como afistomáticas e pequenas, medindo em média $1,8 \mathrm{~mm}$ de largura e comprimentos diferentes para o verão $(20,6 \mathrm{~mm})$ e inverno $(26,1 \mathrm{~mm})$.

A superfície adaxial da lâmina foliar, em vista frontal, apresentou sulcos e saliências de forma regular. Sua epiderme é papilosa e com estômatos (Figura 3) e micropêlos (Figura 4) localizados nos sulcos; estes últimos, do padrão anatômico "panicóide" (sensu Amarasinghe \& Watson, 1988). A superfície abaxial apresentouse sem sulcos e saliências, porém levemente ondulada, com estômatos e micropêlos distribuídos nas faixas intercostais. Os estômatos distribuem-se regularmente ao longo da lâmina, enquanto os micropêlos, ocorrem de maneira irregular (Figura 5).

As médias globais do número de micropêlos e estomâtos nos 14 meses estudados (Tabela 2) evidenciaram densidades maiores na superfície adaxial: 4,4 vezes para micropêlos e 2,3 vezes para estômatos. A presença de estômatos em ambas as superfícies, assim como grande variação quanto ao número, foram consideradas características xeromórficas das plantas que crescem em condições climáticas extremas, como resposta adptativa ao estresse (Gindel, 1969 a e b). Esta hipótese pode ser levantada para $P$. vaginatum já que se encontra num ambiente estressante, pela alta salinidade da água intersticial, em períodos de baixa pluviosidade e de alta evaporação, acompanhados de altas temperaturas. $\mathrm{O}$ fato de a superfície adaxial possuir maior número de estômatos pode estar relacionando com a presença de sulcos e com a epiderme papilosa, que proporcionariam uma proteção à desidratação (Figura 3). Mesmo que numericamente as variações de micropêlos e estômatos tenham sido diferentes, estes mantiveram um padrão de proporcionalidade entre as superfícies adaxial e abaxial. As correlações lineares entre ET1 e ET2 e entre MP1 e MP2 foram significativas (repectivamente $r=0,81$ e $r=0,52$ ) confirmando o inter- 
relacionamento das superfícies (Figura 6 e 7); também verificou-se que os somatórios das estruturas (adaxial mais abaxial) não se relacionaram com os parâmetros abióticos. Portanto, as duas superfícies devem ser consideradas separadamente quando se investigam as respostas da espécie às condições ambientais. Entretanto, constatou-se um pequeno aumento de micropêlos na face adaxial durante o verão (março) (Figura 6) que pode ser uma resposta significativa de aumento da temperatura intersticial $(r=0,48)$, juntamente com aumentos de fosfatos dissolvidos $(r=0,58)$. Estas correlações mostram que, possivelmente, os micropêlos respondam à atividade metabólica, de certa maneira regulada fisiológica e bioquimicamente pela temperatura. A variação mensal do número de micropêlos da superfície abaxial foi semelhante nos anos de 1989 e 1990, de abril a novembro (outono, inverno e primavera), (Figura 6) demostrando o mesmo padrão de comportamento nos períodos onde a temperatura e salinidade intersticial oscilaram entre limites menos drásticos. Contrariamente ao que foi postulado por Lipschitz \& Waisel (1982), as variações no número de micropêlos em $P$. vaginatum não estão correlacionadas
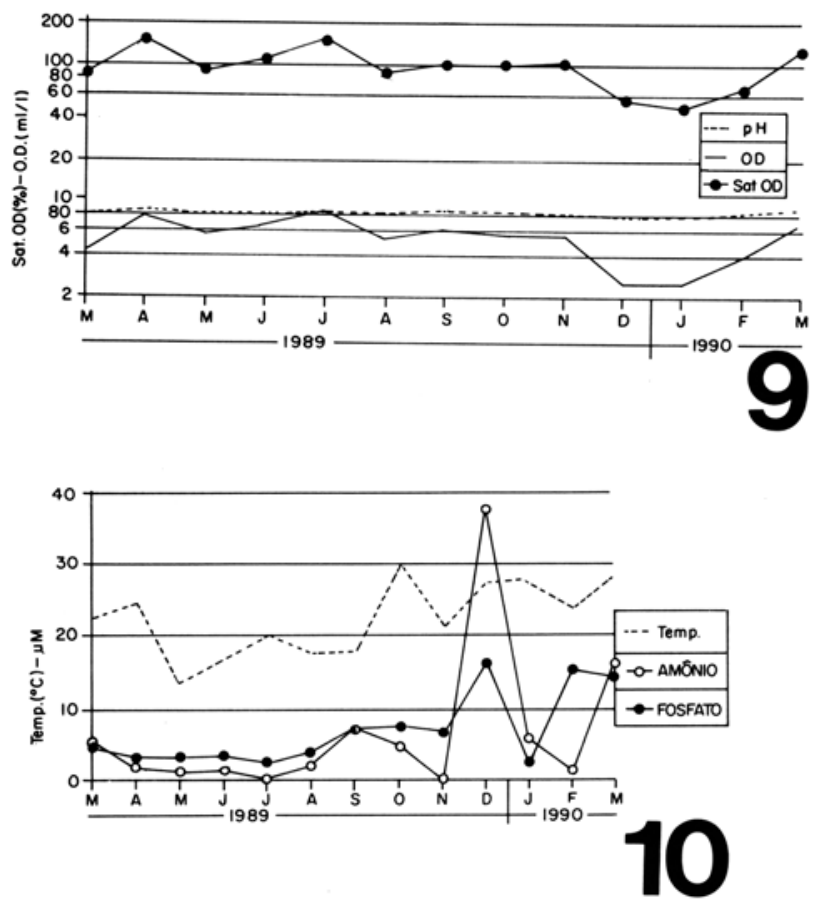

Figura 9 a 10: 9. Variação mensal do oxigênio dissolvido (O.D.) e percentual de saturação em oxigênio (Sat. O.D.) e pH da água superficial. 10. Variação mensal do amônio e do fosfato da água superficial e temperatura superficial. 
Tabela 2 - Médias das variáveis estudadas durante 14 meses com seus respectivos valores de desvio padrão e coeficiente de variação.

\begin{tabular}{lccccc}
\hline Variáveis & $\begin{array}{l}\text { Média } \\
\text { Mínima }\end{array}$ & $\begin{array}{l}\text { Média } \\
\text { Máxima }\end{array}$ & $\begin{array}{l}\text { Média } \\
\text { Geral(x) }\end{array}$ & $\begin{array}{l}\text { Desvio } \\
\text { Padrão(s) }\end{array}$ & $\begin{array}{l}\text { Coeficiente de } \\
\text { Variaçāo,CV(\%) }\end{array}$ \\
\hline $\begin{array}{l}\text { Temperatura } \\
\text { Intersticial }\end{array}$ & 11,4 & 26,60 & 19,48 & 4,56 & 23 \\
\multicolumn{1}{c}{ Salinidade } & & & & & \\
Intersticial & 8,20 & 25,00 & 15,28 & 4,82 & 31 \\
& & & & & \\
chuva & 2,60 & 66,00 & 37,37 & 20,90 & 55 \\
MP1 & 4,67 & 9,81 & 6,95 & 1,65 & 25 \\
MP2 & 0,78 & 2,33 & 1,56 & 0,44 & 27 \\
ET1 & 25,20 & 39,94 & 31,49 & 4,59 & 14 \\
ET2 & 8,94 & 26,29 & 13,63 & 4,40 & 32 \\
\hline
\end{tabular}

com a salinidade. Outro fato a considerar é que estes micropêlos exibem padrão anatômico "panicoide", (Figura 4) o qual não apresenta característica estruturais e ultraestruturais para a secreção de sal (Amarasinghe \& Watson, 1988 e 1989). Portanto, é provavel que a espécie apresente-se bem adaptada ao meio salobre, possuindo outros tipos de mecanismo de tolerância ao sal, que não o secretório. Com o advento das chuvas os estômatos (ET2) mantiveram um comportamento predominante inverso $(\mathrm{r}=-0,47)$, característica descrita por Maximov (1931) como adptação à dessecação. Apenas nos meses de setembro e outubro de 1989 houve uma relação direta do ET2 com a precipitação (Figura 7), provavelmente ligado à frequência de ventos fortes que intensificariam a perda de água levando a planta à seca fisiológica, neste período. A correlação inversa com a pluviosidade pode estar ligada à evapotranspiração foliar. $\mathrm{O}$ aumento do número de estômatos nos meses de baixos índices pluviométricos foi explicado por Lleras (1977) através da seguinte hipótese (tradução livre dos autores): "Quanto mais xerofíticas as condições, maior a frequência estomática por unidade de área. Assim permitindo uma troca de gases mais eficiente nos periodos em que a umidade relativa é alta, quando o perigo de desidratação excessiva é mínimo". Quanto à salinidade não foram constatadas correlações com o número de estômatos como afirma Waisel (1972) e Dillenburg et al. (1986). Possivelmente este fato tenha ocorrido em virtude da salinidade intersticial manter-se com variações pequenas na rizofera da espécie analisada. 
Conclusão

As superfícies foliar, adaxial e abaxial, devem ser consideradas isoladame..te quando se investigam as respostas de $P$. vaginatum às condições ambientais.

Micropêlos e estômatos na superfície abaxial apresentaram significativa correlação com dados abióticos. A alta densidade estomatal em ambas superfícies foliar sugere à espécie características xeromórficas.

\section{Agradecimentos}

Ao professor Tabajara de Almeida do Departamento de Matemática pela orientação na análise estatística. Às professoras Anita Ursula Gudrun Görgen e Clélia M.P. Pereira do Departamento de Ciências Morfo-biológicas pelo apoio e susgestões do manuscrito e à professora Jaci M. B. Saraiva pelos dados pluviométricos. Ao Senhor Antony R. Baptista pela redação do Abstract.

\section{Referências Bibliográficas}

AMARASINGHE, V. \& WATSON, L. 1988. Comparative ultrastructure of microhairs in grasses. Bot. J. Linn. Soc., 98(4):303-319.

AMARASINGHE, V. \& WATSON, L. 1989. Variation in salt secretory activity of microhairs in grasses. Aust. J. Plant Physiol., 16: 219-229.

ASMUS, H.E., GOMES, M., GARRETA-HARKOT, P.F., 1989. Marismas na região estuarina da Lagoa dos Patos: uma abordagem geomorfológica. I. Simpósio sobre Oceanografia, USP. Resumo p.62.

BECAK, W. \& PAULETE, J., 1976. Técnicas de citologia e histologia. Livros Técnicos e Científicos Editora S.A., Rio de Janeiro. p. 230.

BECKING, L.G., KAPLAN, I.R., MOORE, D., 1960. Limits of the natural environment in terms of $\mathrm{pH}$ and oxidation-reduction potentials. J. Geol., 68(3):243-284.

CHAPMAN, V.J., 1974. Salt-marshes and deserts of the world. 2nd. ed., Verlag J. Cramer, Germany.

DELAUNE, R.D., REDDY, C.N., PATRICK JR., W.H., 1981. Organic matter decomposition in soil as influenced by $\mathrm{pH}$ and redox conditions Soil Biol. Biochem., 13:533-534.

DILLENBURG, L.R., ROSA, L.M.G., OLIVEIRA, P.L. de, 1986. Anatomia foliar de Blutaparon portulacoides (St. Hill.) Mears (AMARANTHACEAE) sob condições salinas e não salinas. Iheringia ser. Bot., Porto Alegre, (39):151164.

GINDEL, I., 1969 a. Stomatal number and size as related to soil moisture in tree xerophytes in Israel. Ecology, 50:263-267.

GINDEL, I., 1969 b. Stomata constellation in the leaves of cotton, maize, and wheat plants as a function of the soil moisture and environment. Physiol. 
PLant, 22:1143-1151.

GRASSHOFF, L. EHRHARDT, M., KREMHING, K., (eds.) 1983 Methods of seawater analysis. 2nd ed., Verlay Chemie, Germany.

HAMBRICK III, G.A., DELAUNE, R.D., PATRICK JR., W.H., 1980. Effect of estuarine sediment $\mathrm{pH}$ and oxidation-reduction potential on microbial hidrocarbon degradation. Appl. Environ. Microbiol., 40(2):365-369.

KHALID, R.A, PATRICK JR, W.H., GAMBRELL, R.P., 1978. Effect of disolved oxigen on chemical transformation of leavy metals, phosphorus, and nitrogen in an estuarine sediment. Estuarine and Coastal Marine Science, 6:21-25.

LEVITT, J., 1980. Responses of plants to environmental stresses. II. Water, radiation, salt, and other stresses. Academic Press, New York.

LIPHSCHITZ, N., WAISEL, Y., 1982. Adaptation of plants to saline environments: salt excretion and glandular structures. In SEN, D.N., RAJPUROHIT, K.S. Contribution to the ecology of halophytes. Boston. pp 197-214.

LLERAS, E., 1977. Differences in stomatal number per unit area within the same species under different micro-environmental conditions: A working hypothesis. Acta Amazonica, 7(4):473-476.

MAÀCZ, G.J. \& VÁGAS, E., 1961. A new method for staining of cellulose and lignified cell-walls. Mikroskopie, 16(1-2):40-43.

MAXIMOV, N.A. 1931. The physiological significance of the xeromorphic structutre of plants. J. Ecol., 19:272-282.

NIXON, S.W., 1982. Nutrients dynamics, primary production and fisheries yields of lagoons. Oceanol. Acta, S.P.: 357-371.

PATRICK JR, W.H., DELAUNE, R.D., 1977. Chemical and biological redox systems affecting nutrient availability in the coastal wetlands. Geocience Man., 18:131-137.

POMEROY, L.R., SMITH, E.E., GRANT, C.M.. 1965. The exchange of phosphate between estuarine water and sediments. Limnol. Oceanogr., 10(2):167-172.

POMEROY, L.R., IMBERGER, J. 1981. The physical and chemical environment. In: POMEROY, L.R., WIEGERT, R.G. The ecology of a salt marsh. Ed. Springer Verlag., New York.

WAISEL, Y., 1972. Biology of halophythes, New York, Academic Press.

WEBB, J.W., 1983. Soil water salinity variations and their effects on Spartina alterniflora. Contrib. in Marine Science, 26:1-13. 